\title{
Internet-Based HIV Self-Testing Among Men Who Have Sex With Men Through Pre-exposure Prophylaxis: 3-Month Prospective Cohort Analysis From China
}

Jing Zhang ${ }^{1,2,3,4}$, PhD; Joseph Tucker, ${ }^{5,6}$ PhD; Weiming Tang ${ }^{6,7}$, PhD; Hongyi Wang ${ }^{1,2,3,4}$, PhD; Zhenxing Chu ${ }^{1,2,3,4}$, $\mathrm{PhD}$; Qinghai $\mathrm{Hu}^{1,2,3,4}, \mathrm{PhD}$; Xiaojie Huang ${ }^{8}$, $\mathrm{PhD}$; Yaokai Chen ${ }^{9}$, PhD; Hui Wang ${ }^{10}, \mathrm{PhD}$; Xiaoqing He ${ }^{9}, \mathrm{MD}$; Yao $\mathrm{Li}^{9}$, MD; Lukun Zhang ${ }^{10}$, PhD; Zhili Hu ${ }^{1,2,3,}$, MPH; Rantong Bao ${ }^{1,2,3,4}, \mathrm{MPH}$; Shangcao Li ${ }^{1,2,3,4}, \mathrm{MPH}$; Hang Li ${ }^{1,2,3,4}$, MPH; Haibo Ding ${ }^{1,2,3,4}$, PhD; Yongjun Jiang ${ }^{1,2,3,4}$, PhD; Wenqing Geng ${ }^{1,2,3,4}$, PhD; Junjie $\mathrm{Xu}^{1,2,3,4^{*}}$, PhD; Hong Shang ${ }^{1,2,3,4^{*}}, \mathrm{PhD}$

\footnotetext{
${ }^{1}$ NHC Key Laboratory of AIDS Immunology, National Clinical Research Center for Laboratory Medicine, The First Affiliated Hospital of China Medical University, Shenyang, China

${ }^{2}$ Key Laboratory of AIDS Immunology, Chinese Academy of Medical Sciences, Shenyang, China

${ }^{3}$ Key Laboratory of AIDS Immunology of Liaoning Province, Shenyang, China

${ }^{4}$ Collaborative Innovation Center for Diagnosis and Treatment of Infectious Diseases, Zhejiang University, Hangzhou, China

${ }^{5}$ Faculty of Infectious and Tropical Diseases, London School of Hygiene and Tropical Medicine, London, United Kingdom

${ }^{6}$ University of North Carolina at Chapel Hill Project-China, Guangzhou, China

${ }^{7}$ Dermatology Hospital of Southern Medical University, Guangzhou, China

${ }^{8}$ Center for Infectious Diseases, Beijing YouAn Hospital, Capital Medical University, Beijing, China

${ }^{9}$ Division of Infectious Diseases, Chongqing Public Health Medical Center, Chongqing, China

${ }^{10}$ Department of Infectious Diseases, Shenzhen Third People's Hospital, Shenzhen, China

*these authors contributed equally
}

\section{Corresponding Author:}

Hong Shang, PhD

NHC Key Laboratory of AIDS Immunology

National Clinical Research Center for Laboratory Medicine

The First Affiliated Hospital of China Medical University

No. 155 Nanjingbei Street

Shenyang, 110001

China

Phone: 8683282634

Email: hongshang100@hotmail.com

\section{Abstract}

Background: Routine HIV testing accompanied with pre-exposure prophylaxis (PrEP) requires innovative support in a real-world setting.

Objective: This study aimed to determine the usage of HIV self-testing (HIVST) kits and their secondary distribution to partners among men who have sex with men (MSM) in China, who use PrEP, in an observational study between 2018 and 2019.

Methods: In 4 major cities in China, we prospectively followed-up MSM from the China Real-world oral PrEP demonstration study, which provides daily or on-demand PrEP for 12 months, to assess the usage and secondary distribution of HIVST on quarterly follow-ups. Half of the PrEP users were randomized to receive 2 HIVSTs per month in addition to quarterly facility-based HIV testing. We evaluated the feasibility of providing HIVST to PrEP users.

Results: We recruited 939 MSM and randomized 471 to receive HIVST, among whom 235 (49.9\%) were daily and $236(50.1 \%)$ were on-demand PrEP users. At baseline, the median age was 29 years, $390(82.0 \%)$ men had at least college-level education, and $119(25.3 \%)$ had never undergone facility-based HIV testing before. Three months after PrEP initiation, 341 (74.5\%) men had used the HIVST provided to them and found it very easy to use. Among them, 180 of 341 (52.8\%) men had distributed the HIVST kits it to other MSM, and 132 (51.6\%) among the 256 men who returned HIVST results reported that used it with their 
sexual partners at the onset of intercourse. Participants on daily PrEP were more likely to use HIVST (adjusted hazard ratio=1.3, 95\% CI 1.0-1.6) and distribute HIVST kits (adjusted hazard ratio=1.3, 95\% CI 1.1-1.7) than those using on-demand PrEP.

Conclusions: MSM who used PrEP had a high rate of usage and secondary distribution of HIVST kits, especially among those on daily PrEP, which suggested high feasibility and necessity for HIVST after PrEP initiation. Assuming that fourth-generation HIVST kits are available, HIVST may be able to replace facility-based HIV testing to a certain extent.

Trial Registration: Chinese Clinical Trial Registry ChiCTR1800020374; https://www.chictr.org.cn/showprojen.aspx?proj=32481 International Registered Report Identifier (IRRID): RR2-10.1136/bmjopen-2019-036231

(J Med Internet Res 2021;23(8):e23978) doi: 10.2196/23978

\section{KEYWORDS}

HIV self-testing; men who have sex with men; pre-exposure prophylaxis; secondary distribution; usage

\section{Introduction}

Oral pre-exposure prophylaxis (PrEP) can reduce HIV infections among adherent men who have sex with men (MSM) [1-3]. While the adherence to PrEP is only approximately $60 \%$ in the real-world setting [4], it is crucial for all PrEP users to undergo quarterly HIV testing to avoid a breakthrough infection and acquiring resistance to antiretroviral therapy [5].

However, the implementation of PrEP has increased the rate of missing facility-based testing. Almost $30 \%$ of PrEP users did not show up for their first quarterly clinical visits [6], and approximately $40 \%$ of them missed their 6-monthly appointment [7]. Difficulty attending clinical visits and missing laboratory testing has become one of the main reasons for the interruption [8] and discontinuation [9] in PrEP use in clinical settings. Since the outbreak of COVID-19, attendance at facility-based HIV testing became more difficult because of clinic closure, challenges with social distancing, and related difficulties [10]. It is crucial to identify strategies to ensure frequent HIV testing among individuals on PrEP.

In order to improve and expand PrEP uptake, nonclinical PrEP approaches are being piloted, such as central dispensing at pharmacies [11], community venues (eg, automated teller machines in shopping malls) [12], schools, and prisons or jails [13]. These approaches still require periodic HIV testing, often through HIV self-testing (HIVST), and be supplemented with internet-based support, which is a convenient and confidential option for HIV testing, allowing people to take an HIV test and learn the outcome in their own home or at other private locations [14], while mailing and application of the test kit, support consultations during testing, uploading of testing outcomes, and follow-ups can be conducted over the internet $[15,16]$.

HIVST can also promote partner testing through secondary distribution of test kits [17]; that is, an individual who is provided multiple self-test kits can distribute them to sexual partners or to others in their social network [18]. Peers within the key HIV-infected population play an important role in facilitating HIV prevention in that population; for example, by promoting the uptake of HIV testing [19] and linkage to care [20]. Providing multiple HIVST kits to PrEP users and encouraging their secondary distribution would potentially empower MSM using PrEP and the promote HIV prevention within the MSM community.
HIVST technology has advanced in recent years. Third-generation HIVST technology has a testing period of 3 weeks, with high sensitivity and specificity [21]. PrEP recipients can easily administer HIVST at home and know their HIV status at least 4-8 weeks ahead of their next quarterly HIV facility-based test, as recommended by World Health Organization and Centers for Disease Control and Prevention [5]. In such a scenario, HIVST can be used to identify a breakthrough infection earlier and prevent 4-8 weeks of antiretroviral therapy in PrEP that could lead to resistance.

We aimed to assess the usage and secondary distribution of internet-based HIVST kits and their correlates among MSM using PrEP, prospectively. This information can provide evidence regarding the utility of HIVST in the era of PrEP and support a better paired and targeted HIV-testing strategy among PrEP users in the future.

\section{Methods}

\section{Study Design, Setting, and Participants}

We conducted a randomized control trial of HIV self-testing among MSM who are PrEP users (Chinese Clinical Trial Registry\# ChiCTR1800020374). Participants were recruited from among MSM in the ongoing PrEP pragmatic trial (CROPrEP, ChiCTR-IIN-17013762), which provides regimens of daily and on-demand PrEP, in 4 major Chinese cities (Beijing, Shenyang, Chongqing, and Shenzhen) from December 2018 to September 2019. CROPrEP provides all participants standard care of PrEP, including quarterly facility-based HIV testing. Given the well-documented protective effect of PrEP, the sample size of the CROPrEP study at each site was not determined through power calculations. The sample size at each site was increased maximally by fully considering the human resources and capability of each study site [22].

We randomized half of the enrolled PrEP recipients to provide them 2 HIV self-tests per month, in addition to the standard care. The study team has generated a service account on one of the most popular social media in China (WeChat) to provide web-based services on the application of extra testing kits, instructions on self-testing, real-time consultation with the staff, uploading of test outcomes, and follow-up questionnaires. All HIVST kits distributed or secondarily distributed were marked with a serial number. Participants who received HIVST were also encouraged to share them with their male sexual partners. 
All participants were prospectively followed up quarterly. This study adhered to the STROBE (Strengthening the Reporting of Observational studies in Epidemiology) checklist (Multimedia Appendix 1).

The study sites are general hospitals equipped with HIV voluntary counseling and testing clinics and HIV treatment clinics with physicians specialized in infectious diseases in 4 major cities in China: The Youan Hospital of Capital Medical University, Beijing; The First Affiliated Hospital of China Medical University, Shenyang; The Chongqing Public Health Medical Center of Southwest University, Chongqing; and The Third People's Hospital, Shenzhen.

Participants were eligible to participate in this study if they (1) were designated male at birth; (2) have sex with male partners; (3) are aged 18-65 years; (4) report having $\geq 1$ of the following risk factors in the last 6 months: (a) had condomless receptive anal sex with a male partner, (b) had more than 2 male sexual partners, (c) had self-reported sexually transmitted infections (STIs) such as syphilis, gonorrhea, chlamydia, chancroid, or lymphogranuloma venereum, or (d) have ever used postexposure prophylaxis medication, but have not received postexposure prophylaxis medication in the previous month; (5) have a nonreactive outcome on a fourth-generation HIV enzyme-linked immunosorbent assay test at baseline screening and undetectable HIV-1 RNA; (6) have no evidence of severe liver or kidney dysfunction on a comprehensive evaluation (including physical examination, urine test, and blood biochemical examination); and (7) indicate willingness to participate and sign an informed consent form. Individuals were excluded if they (1) are deemed ineligible on eligibility evaluation for the CROPrEP trial, (2) refuse to accept or use the HIVST kits (with reasons recorded), or (3) refuse to sign the informed consent form.

To prevent loss to follow-up bias, the clinicians and study staff provided one-on-one personalized compliance support, counseling, and cohort maintenance during the follow-up period. Furthermore, community-based organizations and the weekly internet-based retention strategies were used to strengthen groupand individual-level supervision of retention and cohort management. This internet-based strategy included interactive peer counseling focusing on study retention; a short message providing routine follow-up visit reminders, along with a live chat.

\section{Measures}

Information on demographic characteristics (including age, education level, marital status, and monthly income), HIV-related risk behavior in the past 3 months (frequency of anal intercourse, and instances of condomless anal intercourse, substance abuse, etc), and testing history for HIV and STIs in the past were collected at baseline through self-administrated questionnaires distributed on each participants' smartphone. The aforementioned information was obtained in accordance with a systematic review that analyzed studies on HIV testing behaviors among MSM in China [23]. Participants were grouped into $<25$-year-old and $\geq 25$-year-old age groups in accordance with the definition of youth of the United Nations [24]. Participants were also grouped by their median monthly income. Measures of monthly income were separated by the median income. Usage of HIVST and secondary distribution of HIVST to male sexual partners and other MSM were recorded at quarterly follow-up among all participants through self-administrated questionnaires on each participants' smartphone. The returned results of photographs of used HIVST were uploaded by participants after they used HIVST kits, and information regarding the place, occasion, and ease of using HIVST was collected. The proportion of HIVST usage was calculated among participants retained at the third month follow-up visit. Furthermore, the proportion of HIVST secondary distribution was calculated among participants who had self-reported usage of HIVST at the third month follow-up visit.

\section{Statistical Analyses}

Statistical analysis was conducted using SPSS (version 20.0, IBM Corp). Demographics, the PrEP regimen, and HIV-related risk behavior in the past 3 months among all participants were expressed as numbers and percentages. Follow-up time was determined as the number of days from the date of enrollment to the date of quarterly follow-up. Univariable and multivariable Cox regression analyses were performed to assess the predictors of self-reported usage of HIVST and secondary distribution of HIVST at the first quarterly follow-up. Variables with $P<.20$ on univariable analysis were included in the multivariable model to avoid the omission of clinically relevant variables, which had an underestimated effect in univariable analysis $[25,26]$. Variables in the final model were selected with a forward stepwise procedure. Hazard ratios (HRs) and adjusted HRs (aHRs) were calculated. On multivariate analysis, $P<.05$ was considered the cut-off for a significant difference. We plotted Kaplan-Meier survival curves for predictors for HIVST usage and their secondary distribution during multivariable Cox regression analysis with $P<.05$ indicating significance.

\section{Ethics Approval}

The study protocol was approved by the ethics review board of the First Affiliated Hospital of China Medical University (IRB-2018-273), Shenyang. Written informed consent was obtained from each participant before collecting study information or blood samples. Participants voluntarily participated in the study and had the right to refuse to answer any question. Participants had the right to withdraw from the study without penalty. The protocols for the CROPrEP trial [25] and this study [27] have been published. This HIVST study among PrEP recipients was registered on the Chinese Clinical Trial Registry (trial ID ChiCTR1800020374).

\section{Results}

\section{Baseline Demographics and Behavioral Characteristics}

A total of 939 MSM were recruited from the CROPrEP trial, with 470 daily PrEP users and 469 on-demand PrEP users. In total, 471 men were randomized to receive 2 HIV self-tests per month, in addition to the standard care, which included 235 (49.0\%) daily PrEP users and 236 (50.1\%) on-demand PrEP users.

The median age of these 471 participants at baseline was 29 years (quantile 25-35 years); among them, 390 (82.0\%) had an 
education level of undergraduate and above, $241(51.2 \%)$ had a monthly income of less than US \$857, and 266 (56.5\%) were single. Regarding HIV-related risk behavior in the past 3 months, $165(35.0 \%)$ individuals had had anal intercourse every week and $234(49.7 \%)$ had had anal intercourse every month, $312(66.2 \%)$ of them had condomless anal intercourse with male sexual partners, $226(48.0 \%)$ used Poppers in the previous 3 months, and 103 (22.5\%) had participated in group sex. In total, $39(8.3 \%)$ of them self-reported having STI-related symptoms in the previous 12 months. Further, $375(79.6 \%)$ participants self-reported having used HIVST in the past, and 352 (74.7\%) reported having undergone facility-based HIV testing in the past (Table 1). 
Table 1. Baseline characteristics of pre-exposure prophylaxis recipients carrying out HIV self-testing in 4 major cities of China (N=471).

\begin{tabular}{|c|c|}
\hline Variable & Participants, n (\%) \\
\hline \multicolumn{2}{|l|}{ Pre-exposure prophylaxis regimen } \\
\hline Daily & $235(49.9)$ \\
\hline On-demand & $236(50.1)$ \\
\hline \multicolumn{2}{|l|}{ Age (median 29.0 years, quantiles $25.0-35.0$ years) } \\
\hline$<25$ & $84(17.8)$ \\
\hline$\geq 25$ & $387(82.2)$ \\
\hline \multicolumn{2}{|l|}{ Education level } \\
\hline Senior high and below & $81(17.2)$ \\
\hline Undergraduate and above & $390(82.8)$ \\
\hline \multicolumn{2}{|l|}{ Monthly income (US \$) } \\
\hline$\leq 857$ & $241(51.2)$ \\
\hline$\geq 858$ & $230(48.8)$ \\
\hline \multicolumn{2}{|l|}{ Marital status } \\
\hline Single & $266(56.5)$ \\
\hline Married or cohabiting with a female & $30(6.4)$ \\
\hline In a relationship or cohabitating with a male & $175(37.2)$ \\
\hline \multicolumn{2}{|l|}{ Frequency of anal intercourse in the past 3 months } \\
\hline Every day & $8(1.7)$ \\
\hline Every week & $165(35.0)$ \\
\hline Every month & $234(49.7)$ \\
\hline Less than once a month & $64(13.6)$ \\
\hline \multicolumn{2}{|c|}{ Had condomless anal intercourse in the previous 3 months } \\
\hline Yes & $312(66.2)$ \\
\hline No & $159(33.8)$ \\
\hline \multicolumn{2}{|l|}{ Had used Poppers in the previous 3 months } \\
\hline Yes & $226(48.0)$ \\
\hline No & $245(52.0)$ \\
\hline \multicolumn{2}{|l|}{ Had group sex in the previous 3 months ${ }^{a}$} \\
\hline Yes & $103(22.5)$ \\
\hline No & $354(77.5)$ \\
\hline \multicolumn{2}{|c|}{ Had sexually transmitted infection-related symptoms in the previous 12 months } \\
\hline Yes & $39(8.3)$ \\
\hline No & $432(91.7)$ \\
\hline \multicolumn{2}{|l|}{ Have ever used HIV self-testing in the past } \\
\hline Yes & $375(79.6)$ \\
\hline No & $96(20.4)$ \\
\hline \multicolumn{2}{|c|}{ Have ever undergone facility-based HIV testing in the past } \\
\hline Yes & $352(74.7)$ \\
\hline No & $119(25.3)$ \\
\hline
\end{tabular}

${ }^{\mathrm{a}}$ There were 14 missing data. 


\section{Usage, Returning Results, and Sharing of HIVST at the First Quarterly Follow-ups}

Among these 471 men, 458 men were retained at the first quarterly follow-up, resulting in a retention rate of $97.2 \%$. At the first quarterly of PrEP initiation, a total of 341 (74.5\%) participants self-reported that they had used the HIVST in the past 3 months, among whom $256(75.1 \%)$ returned HIVST testing outcomes by uploading photographs of the used HIVST kits marked with a serial number. In total, 260 (76.2\%) men self-reported that they had recommended HIVST to their male sexual partners or gay friends, and $180(52.8 \%)$ participants self-reported that they had shared their HIVST kits with the male sexual partners or gay friends. Among the 256 participants who had returned HIVST outcomes, the most frequent place of using HIVST was at home ( $\mathrm{n}=218,85.2 \%)$. In total, $132(51.6 \%)$ men reported that HIVST was used immediately before or after sexual intercourse with their male sexual partners (Figure 1).

Figure 1. Study flow diagram. HIVST: HIV self-testing.

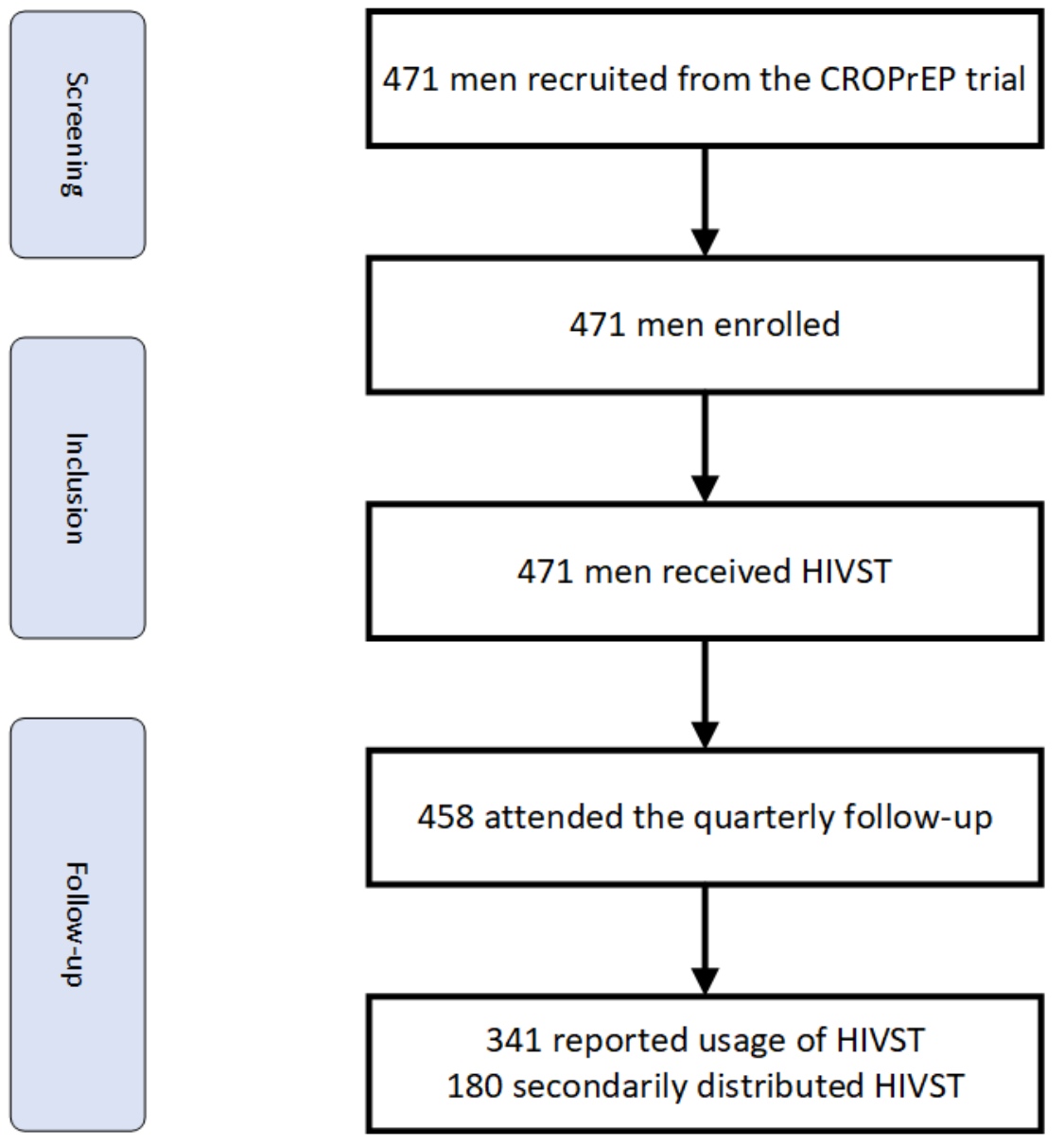

\section{Correlation of Self-Reported Usage of HIVST on Quarterly Follow-up}

On univariable Cox regression analysis, men with the following variables were more likely to use HIVST during follow-up: being on daily PrEP (vs on-demand PrEP, HR=1.273, 95\% CI 1.028-1.576; $P=.03$ ), having an education level of senior high or below (vs college and above, $\mathrm{HR}=1.393,95 \%$ CI 1.054-1.841; $P=.02$ ), having STI-related symptoms in the previous 12 months (vs not having symptoms, HR=1.384, 95\% CI 0.956-2.004; $P=.09$ ), having ever used HIVST in the past (vs having used HIVST in the past, $\mathrm{HR}=1.492,95 \%$ CI $1.102-2.020 ; P=.01)$. Participants with the following variables were less likely to use HIVST: having had anal intercourse every day in the past 3 months (vs less than once a month, HR=0.396, 95\% CI $0.143-1.101 ; P=.08)$, having had condomless anal intercourse in the past 3 months (vs not having had condomless anal intercourse, $\mathrm{HR}=0.825,95 \%$ CI 0.687-0.990; $P=.04$ ) (Table 2).

After the forward stepwise procedure, all variables with $P<.20$ on univariable regression analysis were included in the multivariable regression model, and participants with the following variables were more likely to use HIVST during follow-ups: being on daily PrEP (vs on-demand PrEP, $\mathrm{aHR}=1.298,95 \%$ CI 1.047-1.608; $P=.02$ ), having an education level of senior high or below (vs undergraduate and above, aHR=1.482, 95\% CI 1.119-1.964; $P=.006$ ), and having used HIVST in the past (vs not having used HIVST in the past, $\mathrm{aHR}=1.642$, 95\% CI 1.205-2.242; $P=.002$ ). Furthermore, participants who self-reported having used Poppers in the past 3 months (vs those not having used Poppers in the past 3 months, aHR $=0.788,95 \%$ CI $0.633-9.981 ; P=.03)$ were less likely to use HIVST (Table 2 and Figure 2). 
Table 2. Cox regression model of correlates of usage of HIV self-testing among pre-exposure prophylaxis recipients within 3 months of treatment initiation in 4 major cities in China $(\mathrm{N}=471)$.

\begin{tabular}{|c|c|c|c|c|c|c|c|c|}
\hline \multirow[t]{2}{*}{ Variable } & \multicolumn{4}{|c|}{ Usage of HIV self-testing } & \multicolumn{4}{|c|}{ Secondary distribution of HIV self-test kits } \\
\hline & $\begin{array}{l}\text { Hazard ratio } \\
(95 \% \text { CI })\end{array}$ & $P$ value & $\begin{array}{l}\text { Adjusted hazard } \\
\text { ratio }(95 \% \mathrm{CI})^{\mathrm{a}}\end{array}$ & $P$ value & $\begin{array}{l}\text { Hazard ratio } \\
(95 \% \text { CI })\end{array}$ & $P$ value & $\begin{array}{l}\text { Adjusted hazard } \\
\text { ratio }(95 \% \mathrm{CI})\end{array}$ & $P$ value \\
\hline $\begin{array}{l}\text { Pre-exposure prophylaxis regimen } \\
\text { of daily (vs on-demand) users }\end{array}$ & $\begin{array}{l}1.273 \\
(1.028-1.576)\end{array}$ & .03 & $\begin{array}{l}1.298 \\
(1.047-1.608)\end{array}$ & .02 & $\begin{array}{l}1.343 \\
(1.072-1.682)\end{array}$ & .01 & $\begin{array}{l}1.352 \\
(1.079-1.694)\end{array}$ & .009 \\
\hline Age $<25$ years & $\begin{array}{l}0.990 \\
(0.751-1.307)\end{array}$ & .95 & ${ }^{b}$ & - & $\begin{array}{l}1.066 \\
(0.739-1.539)\end{array}$ & .73 & - & - \\
\hline $\begin{array}{l}\text { Education level of high school and } \\
\text { below }\end{array}$ & $\begin{array}{l}1.393 \\
(1.054-1.841)\end{array}$ & .02 & $\begin{array}{l}1.482 \\
(1.119-1.964)\end{array}$ & .006 & $\begin{array}{l}1.151 \\
(0.840-1.578)\end{array}$ & .38 & - & - \\
\hline Monthly income <US $\$ 857$ & $\begin{array}{l}1.149 \\
(0.928-1.423)\end{array}$ & .20 & - & - & $\begin{array}{l}1.074 \\
(0.858-1.346)\end{array}$ & .53 & - & - \\
\hline Currently married (vs single) & $\begin{array}{l}1.436 \\
(0.811-2.263)\end{array}$ & .12 & - & - & $\begin{array}{l}1.523 \\
(0.963-2.408)\end{array}$ & .07 & $\begin{array}{l}1.706 \\
(1.074-2.709)\end{array}$ & .02 \\
\hline \multicolumn{9}{|c|}{ Frequency of anal intercourse in the previous 3 months } \\
\hline Every day & 1.0 & $\begin{array}{l}\text { Refer- } \\
\text { ence }\end{array}$ & - & - & 1.0 & $\begin{array}{l}\text { Refer- } \\
\text { ence }\end{array}$ & - & - \\
\hline Every week & $\begin{array}{l}1.969 \\
(0.726-5.342)\end{array}$ & .18 & - & - & $\begin{array}{l}1.480 \\
(0.603-3.634)\end{array}$ & .39 & - & - \\
\hline Every month & $\begin{array}{l}2.102 \\
(0.779-5.673)\end{array}$ & .14 & - & - & $\begin{array}{l}1.511 \\
(0.619-3.688)\end{array}$ & .36 & - & - \\
\hline Less than once a month & $\begin{array}{l}2.523 \\
(0.909-7.004)\end{array}$ & .08 & - & - & $\begin{array}{l}1.481 \\
(0.580-3.783)\end{array}$ & .41 & - & - \\
\hline $\begin{array}{l}\text { Had condomless anal intercourse } \\
\text { in the past } 3 \text { months }\end{array}$ & $\begin{array}{l}0.825 \\
(0.687-0.990)\end{array}$ & .04 & - & - & - & .33 & - & - \\
\hline Used Poppers in the past 3 months & $\begin{array}{l}0.848 \\
(0.684-1.049)\end{array}$ & .13 & $\begin{array}{l}0.788 \\
(0.633-0.981)\end{array}$ & .03 & $\begin{array}{l}0.953 \\
(0.761-1.193)\end{array}$ & .68 & - & - \\
\hline Had group sex in the past 3 months & $\begin{array}{l}1.011 \\
(0.781-1.310)\end{array}$ & .93 & - & - & $\begin{array}{l}0.948 \\
(0.724-1.241)\end{array}$ & .70 & - & - \\
\hline $\begin{array}{l}\text { Had sexually transmitted infec- } \\
\text { tion-related symptoms in the past } \\
12 \text { months }\end{array}$ & $\begin{array}{l}1.384 \\
(0.956-2.004)\end{array}$ & .09 & - & - & $\begin{array}{l}1.154 \\
(0.760-1.753)\end{array}$ & .50 & - & - \\
\hline $\begin{array}{l}\text { Have performed HIV self-testing } \\
\text { in the past }\end{array}$ & $\begin{array}{l}1.492 \\
(1.102-2.020)\end{array}$ & .01 & $\begin{array}{l}1.643 \\
(1.205-2.242)\end{array}$ & .002 & $\begin{array}{l}1.415 \\
(1.034-1.937)\end{array}$ & .03 & $\begin{array}{l}1.464 \\
(1.066-2.009)\end{array}$ & .02 \\
\hline $\begin{array}{l}\text { Have undergone facility-based } \\
\text { HIV testing in the past }\end{array}$ & $\begin{array}{l}1.166 \\
(0.904-1.503)\end{array}$ & .24 & - & - & $\begin{array}{l}1.131 \\
(0.867-1.476)\end{array}$ & .36 & - & - \\
\hline
\end{tabular}

${ }^{\text {a }}$ Variables with $P<.20$ on univariable analysis were included in the multivariable Cox regression model.

b_: not determined. 
Figure 2. Kaplan-Meier survival curves for predictors of HIVST usage. HIVST: HIV self-testing, PrEP: pre-exposure prophylaxis.
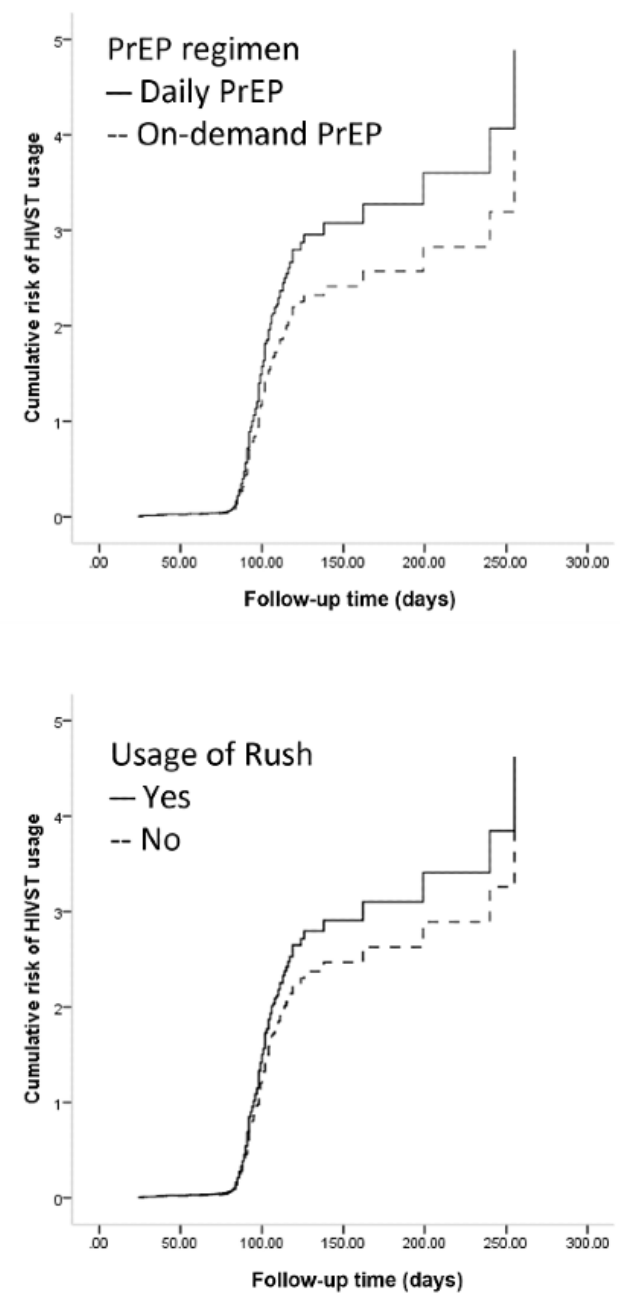

\section{Correlation of Secondary Distribution of HIVST Kits at Quarterly Follow-up}

On univariable Cox regression analysis, participants with the following variables were more likely to secondarily distribute HIVST kits during follow-up: being on daily PrEP (vs on-demand PrEP, HR=1.343, 95\% CI 1.072-1.682; $P=.01)$, being currently married (vs being single, $\mathrm{HR}=1.523,95 \% \mathrm{CI}$ $0.963-2.408 ; P=.07$ ), having ever used HIVST in the past (vs having never used HIVST in the past, $\mathrm{HR}=1.415,95 \% \mathrm{CI}$ 1.034-1.937; $P=.03$ ) (Table 2).
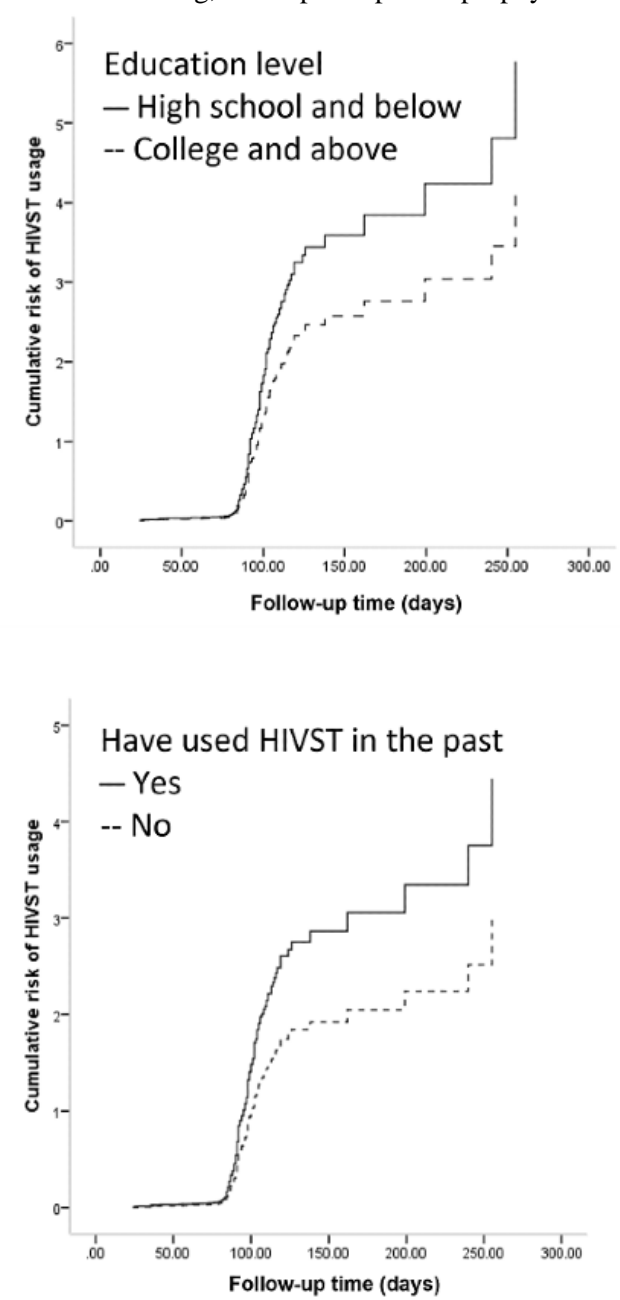

After the stepwise forward procedure, all variables with $P<.20$ on univariable regression were included in the multivariable regression model, and participants with following variables were more likely to secondarily distribute HIVST during follow-ups: being on daily PrEP (vs on-demand PrEP, $\mathrm{aHR}=1.352$, 95\% CI 1.079-1.694; $P=.009)$, being currently married (vs single, aHR=1.706, 95\% CI 1.074-2.709; $P=.02$ ), and having used HIVST in the past (vs not having used HIVST in the past, $\mathrm{aHR}=1.464,95 \%$ CI 1.066-2.009 $P=.02$ ) (Figure $3)$. 
Figure 3. Kaplan-Meier survival curves for predictors of HIVST secondary distribution. HIVST: HIV self-testing; PrEP: pre-exposure prophylaxis.
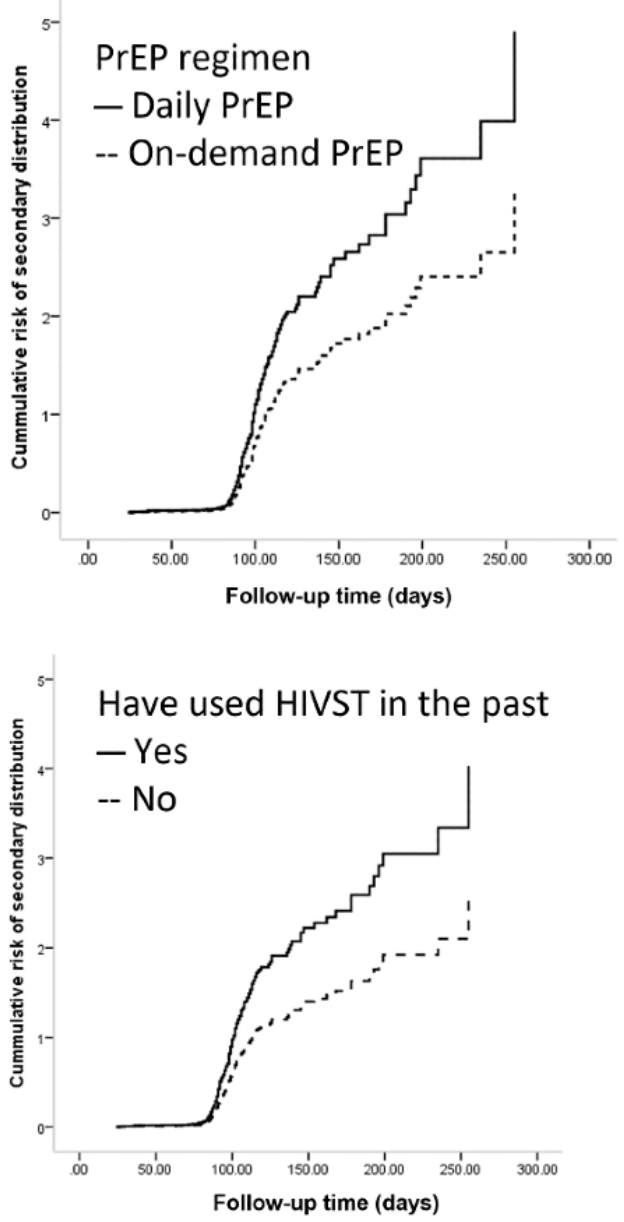

\section{Discussion}

\section{Principal Findings}

We prospectively identified a high rate of usage and secondary distribution of the internet-based HIVST among MSM who are using PrEP in a multicenter pragmatic trial in China, especially among the daily PrEP users. This result warrants the internet-based HIVST as a crucial part of the HIV testing strategy paired with PrEP among the MSM population. Furthermore, the high rate of secondary distribution of HIVST kits and self-testing among sexual partners among PrEP users assures a promising future for peer-initiated expanded HIV testing and maximization of the HIV prevention among the MSM community.

Approximately $80 \%$ of PrEP users have used HIVST within 3 months after PrEP initiation and found it easy to use, reflecting HIV testing behavior among PrEP recipients. Every 4 of 5 of these PrEP users had used HIVST before the initiation of PrEP, which is much higher than the level among the general MSM population in China (20\%-40\%) [28,29]. Since difficulty attending facility-based testing was one of the main reasons for discontinuing PrEP during implementation [8,9], this high usage of HIVST among PrEP users warrants future consideration of substituting some facility-based HIV testing during PrEP and provides evidence in support of HIVST to support PrEP users during the COVID-19 pandemic in the future, since

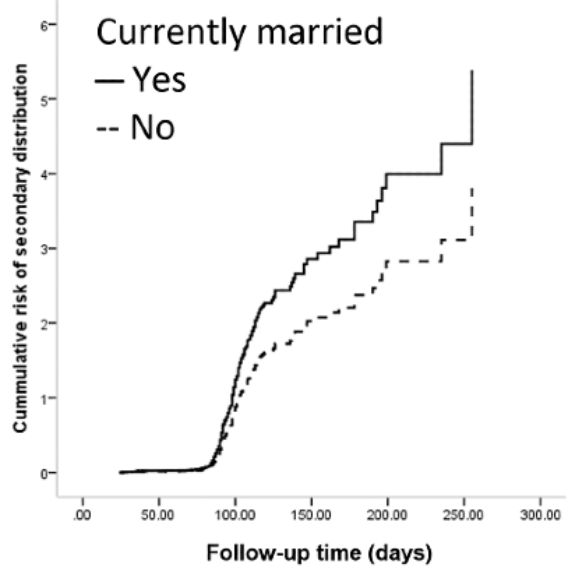

facility-based services and in-person patient-clinician contact has been limited because of the pandemic [30].

Notably, there was a high rate of secondary distribution of HIVST and testing of sexual partners among those who had used HIVST after PrEP initiation. Half of the HIVST was used to test together with their sexual partners immediately before or after intercourse. This is significant because of the limited success and high cost of accessing MSM at clinics or provider-initiated expanded HIV testing strategies [31,32]. According to previous studies, MSM who accept or uptake PrEP were more concerned about their partners' HIV status [33] and had more sexual partners [34], which makes them excellent facilitators for expanded HIV testing among the MSM population. Empowering them with HIVST as a tool to undertake secondary distribution and partner testing can maximize the impact of PrEP on the MSM community via peer-initiated HIV prevention campaigns. Future studies should vigorously pursue and explore the critical role of PrEP users in HIV prevention within the key populations.

Factors promoting the usage and secondary distribution of HIVST among PrEP users were also identified. Men on daily PrEP were more likely to use and secondarily distribute HIVST after PrEP initiation than those on the on-demand regimen. Since most of the HIVST was used immediately before or after sexual intercourse, this correlation can be explained by the fact that MSM on daily PrEP displayed more frequent HIV-related risk behavior and a higher number of sexual partners $[35,36]$. 
According to HIV transmission network studies, MSM with a higher number of sexual partners are associated more firmly with other MSM and had a crucial impact on the network of HIV transmission within the population. This correlation illustrates that MSM on daily PrEP play a more critical role in expanded HIV testing and HIV prevention campaigns as peers among the MSM community. Studies on the social network of PrEP recipients built through HIVST distribution should be actively pursued in the future.

An inhibitor of the use of HIVST among PrEP users is the use of Poppers, which is one of the most popular recreational drugs among MSM worldwide [37]. According to previous studies, Poppers users are more likely to consider themselves PrEP candidates and more likely to be a current PrEP user [38]. However, Poppers usage among MSM is associated with an increased risk of HIV infection $[39,40]$ and a higher probability of participating in group sex [40], which indicates the necessity of timely HIV testing. This inhibitor should draw attention from PrEP providers to address timely HIV testing for PrEP users.

\section{Limitations}

This study has several limitations. First, there is no fourth-generation HIVST kit available currently in China. These are available in the United Kingdom and in other countries and would potentially allow this model to replace some of the facility-based testing. Second, this study was conducted before the COVID-19 pandemic, which might underestimate the usage of HIVST among PrEP users. Third, this study only assessed the usage and secondary distribution within the first 3 months after PrEP initiation, which requires a longer follow-up period to illustrate its long-term usage. Finally, this study only included participants from 4 major cities in China, which did not represent the general MSM population in China.

\section{Conclusions}

Within a pragmatic setting, MSM who are using PrEP had a high rate of usage and secondary distribution of HIVST kits, especially among those on daily PrEP. Offering multiple HIVST to PrEP users to replace some of the facility-based HIV testing and to facilitate expanded HIV testing is feasible and necessary, especially during the COVID-19 pandemic.

\section{Acknowledgments}

The authors would like to thank the community-based organizations of Sunshine, Shenyang; YouAn-Tian Yuan Studio, Beijing; Chongqing Red Ribbon AIDS Care Center, Chongqing; and 258 Rainbow Workshop; Shenzhen, for their help with recruiting and maintaining the participants. We would also like to thank all of the participants for being involved in our study. This work was supported by the Mega-Projects of national science research (13rd Five-Year Plan [2017ZX10201101-002-007]), the Mega-Projects of national science research (12th Five-Year Plan [2012ZX10001006-001-010]), National Natural Science Foundation of China (81872674), and Mega-Projects of national science research (2018ZX10101001-001-003).

\section{Authors' Contributions}

JZ, JJX, and HS conceived and designed the study. JZ, HYW, ZXC, QHH, XJH, YKC, HW, XQH, YL, LKZ, ZLH, RTB, SCL, HL, HBD, YJJ, and WQG performed the study and experiments. JZ, JJX, JDT, and WMT drafted the manuscript. All authors reviewed and approved the final manuscript.

\section{Conflicts of Interest}

None declared.

\section{Multimedia Appendix 1}

STROBE checklist.

[PDF File (Adobe PDF File), 102 KB-Multimedia Appendix 1]

\section{References}

1. Grant RM, Lama JR, Anderson PL, McMahan V, Liu AY, Vargas L, iPrEx Study Team. Preexposure chemoprophylaxis for HIV prevention in men who have sex with men. N Engl J Med 2010 Dec 30;363(27):2587-2599 [FREE Full text] [doi: 10.1056/NEJMoa1011205] [Medline: 21091279]

2. Anderson PL, Glidden DV, Liu A, Buchbinder S, Lama JR, Guanira JV, iPrEx Study Team. Emtricitabine-tenofovir concentrations and pre-exposure prophylaxis efficacy in men who have sex with men. Sci Transl Med 2012 Sep 12;4(151):151ra125 [FREE Full text] [doi: 10.1126/scitranslmed.3004006] [Medline: 22972843]

3. McCormack S, Dunn DT, Desai M, Dolling DI, Gafos M, Gilson R, et al. Pre-exposure prophylaxis to prevent the acquisition of HIV-1 infection (PROUD): effectiveness results from the pilot phase of a pragmatic open-label randomised trial. Lancet 2016 Jan 02;387(10013):53-60 [FREE Full text] [doi: 10.1016/S0140-6736(15)00056-2] [Medline: 26364263]

4. Yun K, Xu J, Zhang J, Li J, Hu Q, Chu Z, et al. Female and younger subjects have lower adherence in PrEP trials: a meta-analysis with implications for the uptake of PrEP service to prevent HIV. Sex Transm Infect 2018 May;94(3):163-168. [doi: 10.1136/sextrans-2017-053217] [Medline: 28756409] 
5. What's New in the Preexposure Prophylaxis for the Prevention of HIV Infection in the United States - 2017 Update - A Clinical Practice Guideline? Centers for Disease Control and Prevention. URL: https://www.cdc.gov/hiv/pdf/risk/prep/ cdc-hiv-prep-guidelines-2017.pdf [accessed 2021-07-23]

6. Parsons JT, Rendina HJ, Lassiter JM, Whitfield THF, Starks TJ, Grov C. Uptake of HIV Pre-Exposure Prophylaxis (PrEP) in a National Cohort of Gay and Bisexual Men in the United States. J Acquir Immune Defic Syndr 2017 Mar 01;74(3):285-292 [FREE Full text] [doi: 10.1097/QAI.0000000000001251] [Medline: 28187084]

7. Hevey MA, Walsh JL, Petroll AE. PrEP Continuation, HIV and STI Testing Rates, and Delivery of Preventive Care in a Clinic-Based Cohort. AIDS Educ Prev 2018 Oct;30(5):393-405 [FREE Full text] [doi: 10.1521/aeap.2018.30.5.393] [Medline: 30332309]

8. Scott HM, Spinelli M, Vittinghoff E, Morehead-Gee A, Hirozawa A, James C, et al. Racial/ethnic and HIV risk category disparities in preexposure prophylaxis discontinuation among patients in publicly funded primary care clinics. AIDS 2019 Nov 15;33(14):2189-2195 [FREE Full text] [doi: 10.1097/QAD.0000000000002347] [Medline: 31436610$]$

9. Rolle C, Onwubiko U, Jo J, Sheth AN, Kelley CF, Holland DP. PrEP Implementation and Persistence in a County Health Department Setting in Atlanta, GA. AIDS Behav 2019 Oct;23(Suppl 3):296-303 [FREE Full text] [doi: 10.1007/s10461-019-02654-x] [Medline: $\underline{31468296}$ ]

10. Jiang H, Zhou Y, Tang W. Maintaining HIV care during the COVID-19 pandemic. Lancet HIV 2020 May;7(5):e308-e309 [FREE Full text] [doi: 10.1016/S2352-3018(20)30105-3] [Medline: 32272084]

11. Tung EL, Thomas A, Eichner A, Shalit P. Implementation of a community pharmacy-based pre-exposure prophylaxis service: a novel model for pre-exposure prophylaxis care. Sex Health 2018 Nov;15(6):556-561. [doi: 10.1071/SH18084] [Medline: 30401342]

12. Stankevitz K, Schwartz K, Hoke T, Li Y, Lanham M, Mahaka I, et al. Reaching at-risk women for PrEP delivery: What can we learn from clinical trials in sub-Saharan Africa? PLoS One 2019;14(6):e0218556 [FREE Full text] [doi: 10.1371/journal.pone.0218556] [Medline: 31226165]

13. Venter WDF. Pre-exposure Prophylaxis: The Delivery Challenge. Front Public Health 2018;6:188 [FREE Full text] [doi: 10.3389/fpubh.2018.00188] [Medline: 30035106 ]

14. Self-Testing. Centers for Disease Control and Prevention. URL: https://www.cdc.gov/hiv/testing/self-testing.html [accessed 2020-04-23]

15. Ngure K, Heffron R, Mugo N, Thomson KA, Irungu E, Njuguna N, et al. Feasibility and acceptability of HIV self-testing among pre-exposure prophylaxis users in Kenya. J Int AIDS Soc 2017 Feb 10;20(1):21234 [FREE Full text] [doi: 10.7448/IAS.20.1.21234] [Medline: 28362073]

16. Ortblad KF, Chanda MM, Musoke DK, Ngabirano T, Mwale M, Nakitende A, et al. Acceptability of HIV self-testing to support pre-exposure prophylaxis among female sex workers in Uganda and Zambia: results from two randomized controlled trials. BMC Infect Dis 2018 Oct 04;18(1):503 [FREE Full text] [doi: 10.1186/s12879-018-3415-z] [Medline: 30286737]

17. Masters SH, Agot K, Obonyo B, Napierala Mavedzenge S, Maman S, Thirumurthy H. Promoting Partner Testing and Couples Testing through Secondary Distribution of HIV Self-Tests: A Randomized Clinical Trial. PLoS Med 2016 Nov;13(11):e1002166 [FREE Full text] [doi: 10.1371/journal.pmed.1002166] [Medline: 27824882]

18. Thirumurthy H, Masters SH, Mavedzenge SN, Maman S, Omanga E, Agot K. Promoting male partner HIV testing and safer sexual decision making through secondary distribution of self-tests by HIV-negative female sex workers and women receiving antenatal and post-partum care in Kenya: a cohort study. Lancet HIV 2016 Jun;3(6):e266-e274 [FREE Full text] [doi: 10.1016/S2352-3018(16)00041-2] [Medline: 27240789]

19. Choko AT, Nanfuka M, Birungi J, Taasi G, Kisembo P, Helleringer S. A pilot trial of the peer-based distribution of HIV self-test kits among fishermen in Bulisa, Uganda. PLoS One 2018;13(11):e0208191 [FREE Full text] [doi: 10.1371/journal.pone.0208191] [Medline: 30496260]

20. Chang LW, Nakigozi G, Billioux VG, Gray RH, Serwadda D, Quinn TC, et al. Effectiveness of peer support on care engagement and preventive care intervention utilization among pre-antiretroviral therapy, HIV-infected adults in Rakai, Uganda: a randomized trial. AIDS Behav 2015 Oct;19(10):1742-1751 [FREE Full text] [doi: 10.1007/s10461-015-1159-y] [Medline: 26271815]

21. Figueroa C, Johnson C, Ford N, Sands A, Dalal S, Meurant R, et al. Reliability of HIV rapid diagnostic tests for self-testing compared with testing by health-care workers: a systematic review and meta-analysis. Lancet HIV 2018 Jun;5(6):e277-e290 [FREE Full text] [doi: 10.1016/S2352-3018(18)30044-4] [Medline: 29703707]

22. Wang H, Zhang Y, Mei Z, Jia Y, Leuba SI, Zhang J, et al. Protocol for a multicenter, real-world study of HIV pre-exposure prophylaxis among men who have sex with men in China (CROPrEP). BMC Infect Dis 2019 Aug 15;19(1):721 [FREE Full text] [doi: 10.1186/s12879-019-4355-y] [Medline: $\underline{31416439}$ ]

23. Zou H, Hu N, Xin Q, Beck J. HIV testing among men who have sex with men in China: a systematic review and meta-analysis. AIDS Behav 2012 Oct;16(7):1717-1728. [doi: 10.1007/s10461-012-0225-y] [Medline: 22677975]

24. Youth. United Nations. URL: https://www.un.org/en/sections/issues-depth/youth-0/index.html [accessed 2020-12-31]

25. Kang S, Cho Y, Park G, Ahn J, Han S, Lee J, et al. Predictors for functionally significant in-stent restenosis: an integrated analysis using coronary angiography, IVUS, and myocardial perfusion imaging. JACC Cardiovasc Imaging 2013 Nov;6(11):1183-1190 [FREE Full text] [doi: 10.1016/j.jcmg.2013.09.006] [Medline: 24229771] 
26. Zhang J, Xu J, Leuba SI, Chu Z, Hu Q, Mao X, et al. Increasing Condomless Anal Intercourse and HIV Prevalence Among Men Who Have Sex with Men Who Have Never Been Tested for HIV Before: A Serial Cross-Sectional Study in Shenyang, China from 2012 to 2016. AIDS Behav 2020 Oct;24(10):2918-2926. [doi: 10.1007/s10461-020-02842-0] [Medline: 32297067]

27. Zhang J, Huang X, Chen Y, Wang H, Zhang Y, Wang H, CROPrEP Group. HIV and other STIs self-testing to reduce risk compensation among men who have sex with men who use oral pre-exposure prophylaxis in China: protocol for a randomised waitlist-controlled trial. BMJ Open 2020 Jul 19;10(7):e036231 [FREE Full text] [doi: 10.1136/bmjopen-2019-036231] [Medline: $\underline{\text { 32690516] }}$

28. Han L, Bien CH, Wei C, Muessig KE, Yang M, Liu F, et al. HIV self-testing among online MSM in China: implications for expanding HIV testing among key populations. J Acquir Immune Defic Syndr 2014 Oct 01;67(2):216-221 [FREE Full text] [doi: 10.1097/QAI.0000000000000278] [Medline: 24991972]

29. Ren X, Wu Z, Mi G, McGoogan JM, Rou K, Zhao Y, et al. HIV care-seeking behaviour after HIV self-testing among men who have sex with men in Beijing, China: a cross-sectional study. Infect Dis Poverty 2017 Jun 28;6(1):112 [FREE Full text] [doi: 10.1186/s40249-017-0326-y] [Medline: 28655340]

30. Self-Testing. Centers for Disease Control and Prevention. URL: https://www.cdc.gov/hiv/testing/self-testing.html [accessed 2020-06-01]

31. Kennedy CE, Fonner VA, Sweat MD, Okero FA, Baggaley R, O'Reilly KR. Provider-initiated HIV testing and counseling in low- and middle-income countries: a systematic review. AIDS Behav 2013 Jun;17(5):1571-1590 [FREE Full text] [doi: 10.1007/s10461-012-0241-y] [Medline: 22752501]

32. Leon N, Mathews C, Lewin S, Osler M, Boulle A, Lombard C. A comparison of linkage to HIV care after provider-initiated HIV testing and counselling (PITC) versus voluntary HIV counselling and testing (VCT) for patients with sexually transmitted infections in Cape Town, South Africa. BMC Health Serv Res 2014 Aug 18;14:350 [FREE Full text] [doi:

10.1186/1472-6963-14-350] [Medline: 25134822]

33. Kwan TH, Lee SS. Bridging Awareness and Acceptance of Pre-Exposure Prophylaxis Among Men Who Have Sex With Men and the Need for Targeting Chemsex and HIV Testing: Cross-Sectional Survey. JMIR Public Health Surveill 2019 Jul 03;5(3):e13083 [FREE Full text] [doi: 10.2196/13083] [Medline: 31271148]

34. Brooks RA, Landrian A, Lazalde G, Galvan FH, Liu H, Chen Y. Predictors of Awareness, Accessibility and Acceptability of Pre-exposure Prophylaxis (PrEP) Among English- and Spanish-Speaking Latino Men Who have Sex with Men in Los Angeles, California. J Immigr Minor Health 2020 Aug;22(4):708-716. [doi: 10.1007/s10903-019-00955-w] [Medline: 31823164]

35. Molina JM, Ghosn J, Béniguel L, Rojas-Castro D, Algarte-Genin M, Pialoux G, Prevenir ANRS study group. Incidence of HIV-infection in the ANRS Prevenir study in Paris region with daily or on-demand PrEP with TDF/FTC. 2018 Jul 26 Presented at: 22nd International AIDS Conference; July 23-27, 2018; Amsterdam URL: http://programme.aids2018.org/ Abstract/Abstract/13278, [doi: 10.1002/jia2.25148]

36. Zimmermann HM, Eekman SW, Achterbergh RC, Schim van der Loeff MF, Prins M, de Vries HJC, Amsterdam PrEP Project team in the HIV Transmission Elimination AMsterdam Consortium (H-TEAM). Motives for choosing, switching and stopping daily or event-driven pre-exposure prophylaxis - a qualitative analysis. J Int AIDS Soc 2019 Oct;22(10):e25389 [FREE Full text] [doi: 10.1002/jia2.25389] [Medline: 31612621]

37. Bae K, Kwon NJ, Han E. A review on the abuse of three NPS (synthetic cannabinoids, kratom, poppers) among youths in Asia. Forensic Sci Int 2018 Nov;292:45-49. [doi: 10.1016/j.forsciint.2018.09.008] [Medline: 30273913]

38. Hambrick HR, Park SH, Schneider JA, Mayer KH, Carrico AW, Sherman SE, et al. Poppers and PrEP: Use of Pre-exposure Prophylaxis Among Men Who Have Sex with Men Who Use Inhaled Nitrites. AIDS Behav 2018 Nov;22(11):3658-3672 [FREE Full text] [doi: 10.1007/s10461-018-2139-9] [Medline: 29744767]

39. Xu J, Zhang C, Hu Q, Chu Z, Zhang J, Li Y, et al. Recreational drug use and risks of HIV and sexually transmitted infections among Chinese men who have sex with men: Mediation through multiple sexual partnerships. BMC Infect Dis 2014 Dec 02;14:642 [FREE Full text] [doi: 10.1186/s12879-014-0642-9] [Medline: 25443542]

40. Zhao P, Tang S, Wang C, Zhang Y, Best J, Tangthanasup TM, et al. Recreational Drug Use among Chinese MSM and Transgender Individuals: Results from a National Online Cross-Sectional Study. PLoS One 2017;12(1):e0170024 [FREE Full text] [doi: 10.1371/journal.pone.0170024] [Medline: 28107391]

\author{
Abbreviations \\ aHR: adjusted hazard ratio \\ HIVST: HIV self-testing \\ HR: hazard ratio \\ PrEP: pre-exposure prophylaxis \\ STI: sexually transmitted infection
}


Edited by R Kukafka; submitted 24.09.20; peer-reviewed by A Botero Carvajal, D Su; comments to author 08.11.20; revised version received 03.01.21; accepted 16.03.21; published 27.08.21

Please cite as:

Zhang J, Tucker J, Tang W, Wang H, Chu Z, Hu Q, Huang X, Chen Y, Wang H, He X, Li Y, Zhang L, Hu Z, Bao R, Li S, Li H, Ding H, Jiang Y, Geng W, Xu J, Shang $H$

Internet-Based HIV Self-Testing Among Men Who Have Sex With Men Through Pre-exposure Prophylaxis: 3-Month Prospective Cohort Analysis From China

J Med Internet Res 2021;23(8):e23978

URL: https://www.jmir.org/2021/8/e23978

doi: $\underline{10.2196 / 23978}$

PMID: 34448709

(CJing Zhang, Joseph Tucker, Weiming Tang, Hongyi Wang, Zhenxing Chu, Qinghai Hu, Xiaojie Huang, Yaokai Chen, Hui Wang, Xiaoqing He, Yao Li, Lukun Zhang, Zhili Hu, Rantong Bao, Shangcao Li, Hang Li, Haibo Ding, Yongjun Jiang, Wenqing Geng, Junjie Xu, Hong Shang. Originally published in the Journal of Medical Internet Research (https://www.jmir.org), 27.08.2021. This is an open-access article distributed under the terms of the Creative Commons Attribution License (https://creativecommons.org/licenses/by/4.0/), which permits unrestricted use, distribution, and reproduction in any medium, provided the original work, first published in the Journal of Medical Internet Research, is properly cited. The complete bibliographic information, a link to the original publication on https://www.jmir.org/, as well as this copyright and license information must be included. 